A C T A C H E M I A S C A N D I N A V I C A 15 (1961) 4 4-61

\title{
The Solution Chemistry of Copper and Nickel Complexes with Dimethylglyoxime
}

\author{
DAVID DYRSSEN and MARGARETA HENNICHS
}

Department of Inorganic Chemistry, Royal Institute of Technology, Stockholm 70, Sweden

The distribution of ${ }^{64} \mathrm{Cu}(\mathrm{II})$ at $25^{\circ} \mathrm{C}$ between chloroform and $0.1 \mathrm{M}$ perchlorate solutions has been studied as a function of $\mathrm{H}^{+}$and $\mathrm{HA}$ (dimethylglyoxime) in the aqueous phase and of B (quinoline or dodecylamine) in the organic phase. From the data the following constants have been calculated:

$\mathrm{CuA}_{2} \rightleftharpoons \mathrm{CuA}_{2}$ (in $\mathrm{CHCl}_{3}$ ); $\log \lambda_{2}=-0.93 \pm 0.05$

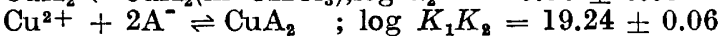

$\mathrm{CuA}_{2}$ (in $\mathrm{CHCl}_{3}$ ) $+\mathrm{B}$ (in $\mathrm{CHCl}_{3}$ ) $\rightleftharpoons \mathrm{CuA}_{2} \mathrm{~B}$ (in $\mathrm{CHCl}_{3}$ ); $\log \varkappa_{\mathrm{B}}=2.04$ (quinoline) and 3.36 (dodecylamine). The data give no evidence of CuA+; we conclude that $\log K_{1} \leq \log K_{2}-1.2$.

The solubility of $\mathrm{CuA}_{2}$ in $0.1 \mathrm{M} \mathrm{NaClO}$ and chloroform has been determined. The solutions were saturated by slow filtration through columns packed with solid radioactive $\mathrm{CuA}_{2}$. Results: $7.9_{1} \times 10^{-3} \mathrm{M}$ $\left(0.1 \mathrm{M} \mathrm{NaClO}{ }_{4}\right), 1.05_{3} \times 10^{-3} \mathrm{M}$ (wet chloroform) and $1.02_{3} \times 10^{-3} \mathrm{M}$ (dry chloroform). From a study of the solubility of $\mathrm{CuA}_{2}$ in $0.1 \mathrm{M}$ $\mathrm{Na}\left(\mathrm{OH}, \mathrm{ClO}_{4}\right)$ the hydrolysis constant of $\mathrm{CuA}_{2}$ was determined: $\log \varkappa_{\mathrm{H}}=-10.60$. The solubility of $\mathrm{NiA}_{2}$ in chloroform solutions of quinoline or dodecylamine was studied and no reaction between $\mathrm{NiA}_{2}$ and $\mathrm{B}$ was found.

These results are compared with previous data ${ }^{5}$ on $\mathrm{NiA}_{2}$ and it is concluded that the large differences between $\mathrm{NiA}_{2}$ and $\mathrm{CuA}_{2}$ are due to the fact that $\mathrm{Cu}^{2}+$ in $\mathrm{CuA}_{2}$ has a tendency to be five-coordinated while $\mathrm{Ni}^{2}+$ in $\mathrm{NiA}_{2}$ has only the coordination number of four.

\begin{abstract}
$A^{2}$ $\mathrm{n}$ important contribution to the understanding of the differences of properties between $\mathrm{Ni}$ and $\mathrm{Cu}$-complexes with dimethylglyoxime (HA) has recently been made by Frasson, Bardi and Bezzi ${ }^{1}$ by their $\mathrm{X}$-ray determination of the crystal structure of the copper salt, $\mathrm{CuA}_{2}$. This, together with the determination of the structure of $\mathrm{NiA}_{2}$ by Godycki and Rundle ${ }^{2}$, means that we are now well-informed about the structures of the two compounds in the solid state and can make some guesses about the linkages that determine the lattice energy. In the case of coppe1, $\mathrm{Cu}_{2} \mathrm{~A}_{4}$ dimers are formed in the crystal, while in the case of nickel $\mathrm{NiA}_{2}$ monomers are formed. These units are probably linked with each other in the crystal by van der Waals' forces, but in the case
\end{abstract}


of $\mathrm{NiA}_{2}$ there may also exist long $\mathrm{Ni}-\mathrm{Ni}$ bonds (3.245 $\AA$ against $2.492 \AA$ in the metal ${ }^{3}$ and $3.084 \AA$ in $\mathrm{NiF}_{2}$, which has a rutile lattice ${ }^{4}$ ).

In the solid medium with its rather high density of bond-forming atoms ( $\mathrm{N}$ and $\mathrm{O}$ ) nickel has a coordination number of four in $\mathrm{NiA}_{2}$, except for the two rather long and probably weak metal bonds, while copper forms an additional coordinate link with an oxygen atom in the neighboring $\mathrm{CuA}_{2}$ molecule and therefore has a coordination number of five in the crystal state. Consequently, $\mathrm{Cu}$ does not lie in the same plane as the four metalbonding $\mathrm{N}$ atoms of dimethylglyoxime, while $\mathrm{Ni}$ does.

It is thus quite possible that the forces between the $\mathrm{NiA}_{2}$ or $\mathrm{Cu}_{2} \mathrm{~A}_{4}$ molecules in the solid state (lattice energy) may be of the same order of magnitude and that the solubilities in inert non-solvating solvents may therefore also be about the same for the two salts. A more complete understanding of the differences between $\mathrm{NiA}_{2}$ and $\mathrm{CuA}_{2}$ may therefore be obtained from a study of the solution chemistry of the two complexes.

The work reported here includes the determination of the complexity constants for the reaction $\mathrm{M}^{2+}+2 \mathrm{~A}^{-} \rightleftharpoons \mathrm{MA}_{2}$ by the distribution technique (cf. Dyrssen, Krašovec, and Sillén ${ }^{5}$ for nickel), of the distribution constants of $\mathrm{MA}_{2}$ between chloroform and water, and of the solubilities of $\mathrm{MA}_{2}$ in chloroform. Furthermore, the reaction $\mathrm{MA}_{2}+\mathrm{B} \rightleftharpoons \mathrm{MA}_{2} \mathrm{~B}(\mathrm{~B}=$ quinoline or $n$ dodecylamine) was studied in chloroform.

\section{EXPERIMENTAL}

Chemicals. Chloroform ("Merck's p.a. für Chromatographie") was washed with distilled water to remove the $1 \%$ abs. alcohol and to saturate the solvent with water. Dimethylglyoxime (Kebo's p.a. reagent for nickel) was not further purified or recrystallized. $n$-Dodecylamine (two white crystallized products from Fluka and Light \& Co) had a melting point of $26-28^{\circ} \mathrm{C}$ and was not further purified. Care was taken to avoid contact with $\mathrm{CO}_{2}$ when handling the amine or its solution in chloroform. Quinoline (synthetic product, Kebo puriss., b.p. $235-237^{\circ} \mathrm{C}$ ) and triethanolamine (Fluka, Switzerland, colorless puriss. quality) were also used without further purification. The $\mathrm{NaClO}_{4}$ was made according to a technique used in this laboratory ${ }^{\circ}$. Other chemicals $\left(\mathrm{HClO}_{4}, \mathrm{NH}_{3}\right.$, alcohol, etc.) were of analytical grade.

The radioactive copper, $12.8 \mathrm{~h}{ }^{84} \mathrm{Cu}$, was obtained by irradiation of weighed pieces (about $200 \mathrm{mg}$ ) of pure sheet-copper in the Swedish reactor $\mathrm{R} \mathrm{1}$; the neutron flux used was between 5 and $20 \times 10^{11} \mathrm{n} \mathrm{cm}^{-8} \mathrm{sec}^{-1}$. After irradiation the copper was dissolved in conc. $\mathrm{HNO}_{3}$. This solution was evaporated to dryness and the copper nitrate was dissolved in $25 \mathrm{ml}$ of $0.1 \mathrm{M} \mathrm{HClO}_{4}$. This stock solution was then further diluted with 0.1 $\mathrm{M} \mathrm{NaClO}_{4}$. The purity of the ${ }^{64} \mathrm{Cu}$ nuclide was checked by following the decay over a week.

The radioactive $\mathrm{CuA}_{2}$ was synthetized according to Tschugaeff ${ }^{7}$. However, his method was slightly modified as follows: 10 mmoles of dimethylglyoxime (HA) were dissolved in a hot solution of $2 \mathrm{ml}$ of cone. $\mathrm{NH}_{3} \times 20 \mathrm{ml}$ of abs. alcohol. $5 \mathrm{ml}$ of a hot solution of $1 \mathrm{M} \mathrm{CuSO}_{4}$ with radioactive ${ }^{64} \mathrm{Cu}$ was added. On chilling, $\mathrm{CuA}_{2}$ crystallized out of the dark solution. The crystals were washed with alcohol and dried on filter paper at room temperature.

$\mathrm{NiA}_{2}$ was simply precipitated from a saturated solution of dimethylglyoxime in water with a solution of $\mathrm{NiCl}_{2}$.

Analytical procedures. For the analysis of dimethylglyoxime in $0.1 \mathrm{M} \mathrm{NaClO}_{4}$ and in chloroform solutions, the dimethylglyoxime was reacted with an excess of nickel chloride in an alcohol-chloroform mixture using triethanolamine as a proton-acceptor. The UV light absorption of the $\mathrm{NiA}_{2}$ formed was measured at $365 \mathrm{~m} \mu$. At this wave-length the absorption did not seem to vary with the conc. of quinoline in the chloroform solution. The extinction coefficient of $\mathrm{NiA}_{2}$ at $365 \mathrm{~m} \mu$ is $3356 \mathrm{M}^{-1} \mathrm{~cm}^{-1}$. The same wave-length 
was used for the determination of the solubility of $\mathrm{NiA}_{2}$ in chloroform solutions of quinoline or dodecylamine.

The analysis of the conc. of copper was made radiometrically utilizing the annihilation radiation of the positrons formed in the decay of ${ }^{\circ 1} \mathrm{Cu}$. The gamma quanta were counted in a Tracerlab SC-57 low background well scintillation counter connected with a Tracerlab SC-18A Superscaler or SC-73 Versa/matic II scaler.

Solubility experiments. Solutions of quinoline or $n$-dodecylamine in chloroform were saturated with dimethylglyoxime or its nickel and copper salts, $\mathrm{NiA}_{2}$ and $\mathrm{Cu}_{2}$, by filtering the solutions through columns with a bed 7-10 cm thick at a flow rate of about $1 \mathrm{~cm} \mathrm{~min}{ }^{-1}$. It is an experience at our laboratory that solutions that flow from such columns are saturated. This was checked in our case by filtering some solutions twice through a column (or back-washing), and by variation of the flow rate and column height. The results agreed also with experiments where equilibrium was obtained by shaking the solutions over night. These experiments confirm that the diffusion layer outside the surface of the solid phase is much more effectively broken down in a filtering column than in a shaking process. Solutions of $0.1 \mathrm{M} \mathrm{NaClO}_{4}+0.0001 \mathrm{M} \mathrm{HClO}_{4}$ were saturated with dimethylglyoxime in a similar manner and the solubility of $\mathrm{CuA}_{2}$ in 0.1 $\mathrm{M} \mathrm{Na}\left(\mathrm{OH}, \mathrm{ClO}_{4}\right)$ was studied by the same technique.

Distribution experiments. The two phases (15 ml of each) were made up as follows. The organic phase was either pure chloroform or a solution of quinoline or $n$-dodecylamine in chloroform. Dimethylglyoxime was added as a saturated solution (0.005 M) in $0.1 \mathrm{M} \mathrm{NaClO}_{4}\left(+0.0001 \mathrm{M} \mathrm{HClO}_{4}\right)$. The hydrogen ion concentration of the aqueous layer $([\mathrm{H}+])$ was adjusted with three solutions: $0.09 \mathrm{M} \mathrm{NaClO}_{4}+0.01 \mathrm{M} \mathrm{HClO}, 0.09 \mathrm{M}$ $\mathrm{NaClO}_{4}+0.01 \mathrm{M} \mathrm{Na}$-acetate, and $0.09 \mathrm{M} \mathrm{NaClO}{ }_{4}+0.01 \mathrm{M} \mathrm{NaOH}$. The final volume of the aqueous phase $(15 \mathrm{ml})$ was made up with $0.1 \mathrm{M} \mathrm{NaClO}_{4}$ after addition of radioactive copper (see above).

The two phases were shaken for $1-18 \mathrm{~h}$ and centrifuged. No heating of the solutions was observed after 10 min centrifugation ${ }^{3}$. The value of $-\log \left[\mathrm{H}^{+}\right]$was measured with a glass electrode standardized against a solution of $0.01 \mathrm{M} \mathrm{HClO}_{4}+0.09 \mathrm{M} \mathrm{NaClO}$. $\left(-\log \left[\mathrm{H}^{+}\right]=2.00\right)$. The copper concentration of each phase was measured radiometrically as described above. Care was taken not to contaminate the sample of the chloroform layer with the more active aqueous layer. No difficulties were met in obtaining material balance; the sum of intensities of the two phases was constant for each sample of irradiated copper when corrected for the decay of ${ }^{84} \mathrm{Cu}$.

All experiments were carried out at $25^{\circ} \mathrm{C}$ in constant temperature rooms and the ionic strength of the aqueous solutions was kept constant at $0.1 \mathrm{M}$ using mainly $\mathrm{NaClO}_{4}$.

\section{SYMBOLS AND EQUILIBRIUM* CONSTANTS}

\section{$\mathrm{HA}=$ dimethylglyoxime, $\mathrm{CH}_{3} \mathrm{C}(: \mathrm{NOH}) \mathrm{C}(: \mathrm{NOH}) \mathrm{CH}_{3}$}

$$
\mathrm{B}=\text { quinoline, } \mathrm{C}_{9} \mathrm{H}_{7} \mathrm{~N} \text {, or } n \text {-dodecylamine, } \mathrm{C}_{12} \mathrm{H}_{25} \mathrm{NH}_{2}
$$

$\mathrm{HAc}=$ acetic acid, $\mathrm{CH}_{3} \mathrm{COOH}$

$$
\begin{aligned}
& K_{\mathrm{a}}=\left[\mathrm{H}^{+}\right]\left[\mathrm{A}^{-}\right][\mathrm{HA}]^{-1} \\
& K_{\mathrm{d}}=[\mathrm{HA}]_{\text {org }}[\mathrm{HA}]^{-1} \\
& \left.\left.K_{\mathrm{B}}=[\mathrm{HAB}]_{\mathrm{org}}[\mathrm{HA}]_{\text {org }}^{-1}\right] \mathrm{~B}\right]_{\text {org }}^{-1} \\
& K_{\mathrm{B} 2}=[\mathrm{HAB}]_{\mathrm{org}}[\mathrm{HA}]_{\text {org }}^{-1}[\mathrm{~B}]_{\text {org }}^{-2} \\
& \beta_{1}=\left[\mathrm{MA}^{+}\right]\left[\mathrm{M}^{2+}\right]^{-1}\left[\mathrm{~A}^{-}\right]^{-1} ; \mathrm{M}=\mathrm{Ni} \text { or } \mathrm{Cu} \\
& \beta_{2}=\left[\mathrm{MA}_{2}\right]\left[\mathrm{M}^{2+}\right]^{-1}\left[\mathrm{~A}^{-}\right]^{-2} ; \beta_{1}=K_{1} ; \beta_{2}=K_{1} K_{2} \\
& \lambda_{2}=\left[\mathrm{MA}_{2}\right]_{\text {org }}\left[\mathrm{MA}_{2}\right]^{-1} \\
& x_{\mathrm{B}}=\left[\mathrm{MA}_{2} \mathrm{~B}\right]_{\text {org }}\left[\mathrm{MA}_{2}\right]_{\text {org }}^{-1}[\mathrm{~B}]_{\text {org }}^{-1} \\
& x_{\mathrm{H}}=\left[\mathrm{H}^{+}\right]\left[\mathrm{MA}_{2} \mathrm{OH}^{-}\right]\left[\mathrm{MA}_{2}\right]^{-1}
\end{aligned}
$$

$q=$ net distribution ratio (org/aq)

$[\mathrm{HA}]_{\mathrm{tot}}=$ initial total conc. of $\mathrm{HA}$ in the aqueous phase

$[\mathrm{Cu}]_{\text {tot }}=$ initial total conc. of copper in the aqueous phase.

Acta Chem. Scand. 15 (1961) No. 1 


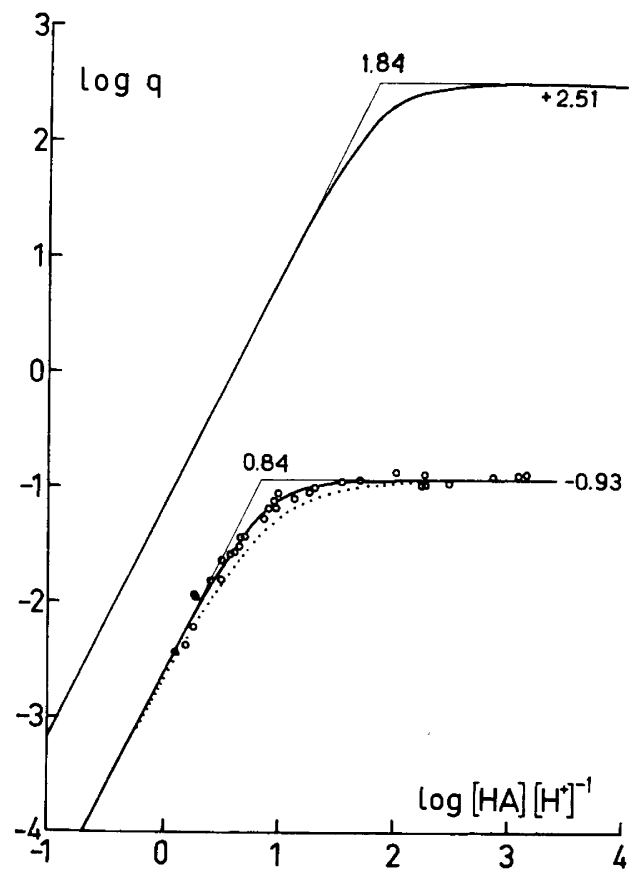

Fig. 1. Distribution of nickel (upper curve) and copper between chloroform and 0.1/M $\mathrm{NaClO}_{4}$ as a function of $\log [\mathrm{HA}]-\log [\mathrm{H}+]$. Normalised curves $Y=-\log \left(1+p v+v^{2}\right)$, $X=-\log v$ in (position of best fit, for $p=0$ (full-drawn) and $p=1$ (dotted). The thin lines are the asymptotes.

\section{COMPLEX FORMATION OF $\mathrm{CuA}_{2}$}

Recently it has been shown by Dyrssen, Krašovec, and Sillén ${ }^{5}$ that the complex formation of nickel with dimethylglyoxime could be studied by the distribution method with reasonably good accuracy. This method is also used here for the determination of $\beta_{2}$ and $\lambda_{2}$ for the copper-dimethylglyoximechloroform system. The general equations in our previous paper ${ }^{5}$ will not be repeated here. The distribution data are given in Table 1 and plotted as $\log q$ against $\log [\mathrm{HA}]\left[\mathrm{H}^{+}\right]^{-1}$ in Fig. 1.

[HA], the free conc. of dimethylglyoxime in the aqueous phase, was calculated from the initial conc. of $\mathrm{HA},[\mathrm{HA}]_{\text {tot }}$, with the following two equations, which allow for the

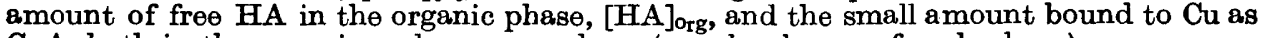
$\mathrm{CuA}_{2}$ both in the organic and aqueous phase (equal volumes of each phase):

$$
\begin{aligned}
{\left[\mathrm{CuA}_{\mathbf{2}}\right] } & =\frac{[\mathrm{Cu}]_{\text {tot }}}{1+\lambda_{2}+10^{1.8^{2}}[\mathrm{H}+]^{2}[\mathrm{HA}]_{\mathrm{tot}}^{-2}} \\
{[\mathrm{HA}] } & =\frac{[\mathrm{HA}]_{\mathrm{tot}}-2\left(1+\lambda_{2}\right)\left[\mathrm{CuA}_{2}\right]}{1+K_{\mathrm{d}}}
\end{aligned}
$$

Acta Chem. Scand. 15 (1961) No. 1 
Table 1. Distribution of $\mathrm{Cu}^{2}+$ between chloroform and $0.1 \mathrm{M}$ perchlorate solutions at $25^{\circ} \mathrm{C}$. The concentrations refer to the initial total concentrations in the aqueous phase. The data are plotted in Fig. 1 as $\log q$ against $\log [\mathrm{HA}]-\log [\mathrm{H}+]$.

\begin{tabular}{|c|c|c|c|c|}
\hline $\begin{array}{l}{[\mathrm{Cu}]_{\text {tot }}} \\
10^{-4} \mathrm{M}\end{array}$ & $\begin{array}{l}{[\mathrm{Ac}]_{\text {tot }}} \\
10^{-3} \mathrm{M}\end{array}$ & $\underset{\left.10^{-3}\right]_{\text {tot }}}{[\mathrm{M}}$ & $\log q$ & $-\log [\mathbf{H}+]$ \\
\hline 0.0396 & 3.33 & 1.57 & -2.44 & 2.94 \\
\hline 1.186 & 1.20 & 1.57 & -2.38 & 3.03 \\
\hline 0.593 & 0 & 1.57 & -2.22 & 3.10 \\
\hline 0.459 & 3.33 & 0.78 & -1.94 & 3.51 \\
\hline 0.777 & 3.33 & 1.67 & -1.95 & 3.19 \\
\hline 3.11 & 1.33 & 1.67 & -1.81 & 3.28 \\
\hline 0.777 & 3.33 & 1.67 & -1.81 & 3.29 \\
\hline 0.777 & 3.33 & 1.67 & -1.64 & $\mathbf{3 . 3 0}$ \\
\hline 0.406 & 1.33 & 1.58 & -1.59 & 3.44 \\
\hline 3.11 & 3.33 & 1.67 & -1.59 & 3.43 \\
\hline 0.459 & 3.33 & 1.56 & -1.43 & 3.50 \\
\hline 0.459 & 3.33 & 1.56 & -1.52 & 3.49 \\
\hline 3.11 & 3.33 & 1.67 & -1.43 & 3.58 \\
\hline 0.593 & 1.33 & 1.57 & -1.18 & 3.77 \\
\hline 0.395 & 1.33 & 1.57 & -1.26 & 3.72 \\
\hline 0.406 & 1.33 & 1.58 & -1.12 & 3.80 \\
\hline 3.11 & 3.33 & 1.67 & -1.27 & 3.78 \\
\hline 0.344 & 2.67 & 2.34 & -1.05 & 3.66 \\
\hline 1.186 & 2.93 & 1.58 & -1.18 & 3.85 \\
\hline 0.395 & 1.33 & 1.57 & -1.10 & 3.97 \\
\hline 0.813 & 0 & 3.15 & -1.05 & 3.81 \\
\hline 0.0396 & 3.33 & 1.57 & -1.01 & 4.13 \\
\hline 0.0396 & 3.33 & 1.57 & -0.95 & 4.37 \\
\hline 0.0396 & 2.00 & 3.15 & -0.94 & 4.23 \\
\hline 0.406 & 2.00 & 3.15 & $-0.87^{*}$ & 4.56 \\
\hline 0.115 & 3.33 & 2.34 & $-0.88 *$ & 4.91 \\
\hline 1.24 & 3.33 & 1.56 & $-0.98 *$ & 5.14 \\
\hline 1.24 & 3.33 & 1.56 & $-0.97^{*}$ & 5.17 \\
\hline 1.24 & 3.33 & 1.56 & $-0.98 *$ & 5.17 \\
\hline 0.932 & 5.00 & 1.25 & $-0.96 *$ & 5.47 \\
\hline 0.0115 & 3.33 & 0.78 & $-0.90 *$ & 6.00 \\
\hline 0.0115 & 3.33 & 1.56 & $-0.89 *$ & 5.92 \\
\hline 0.0115 & 3.33 & 2.34 & $-0.88 *$ & 5.81 \\
\hline
\end{tabular}

* $\lambda_{2}$ was calculated from these experiments by dividing the sum of counts per minute of the organic layers (23 778) with the corresponding value of the aqueous layers (201 800).

The constants $\lambda_{2}=10^{-0.93}$ and $10^{1.82}$ were obtained from a plot log $q$ against log $[\mathrm{HA}]_{\text {tot }}\left[\mathrm{H}^{+}\right]^{-1} . \quad K_{\mathrm{d}}=0.0786$ was obtained by dividing the solubility of dimethylglyoxime in $\mathrm{CHCl}_{3}$ (saturated with water), $3.94 \times 10^{-4} \mathrm{M}$, by that in $0.1 \mathrm{M} \mathrm{NaClO}+0.0001$ $\mathrm{M} \mathrm{HClO}_{4}, 5.01 \times 10^{-3} \mathrm{M}$. In most experiments (se日 Table 1) [Cu $]_{\text {tot }}$ is considerably smaller than [HA] tot. It can therefore not be a serious error to neglect the amount of $\mathrm{A}$ bound as $\mathrm{CuA}+$.

The influence of the acetate ions on the distribution is greater in the case of copper than in the case of nickel as $\lambda_{2} \beta_{2}$ and $\lambda_{2}$ for $\mathrm{MA}_{2}$ are smaller and the constants for the formation of $\mathrm{MAc}+$ and $\mathrm{MAc}_{2}$ are larger than for nickel. However, at low values of [A ${ }^{-}$] (low $\mathrm{pH}$ ) the formation of acetic acid will predominate over the formation of copper acetate complexes, and at high values of $\left[\mathrm{A}^{-}\right]$the dominating complex will be $\mathrm{CuA}$. If one uses the stability constants for the copper-acetate system given by Pedersen and corrected with Kielland's ${ }^{10}$ activity factors, it can be calculated for the acetate concen. trations used, that the lowering of $\log q$ is less than 0.05 in the most sensitive region. This

Acta Chem. Scand. 15 (1961) No. 1 


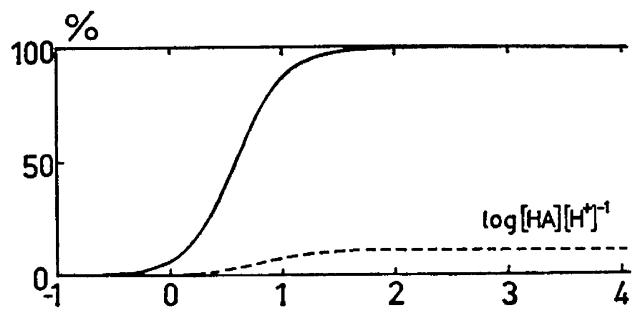

Fig. 2. Percentage of nickel (full-drawn curve) and copper (dashed curve) distributed between chloroform and $0.1 \mathrm{M} \mathrm{NaClO}$ as a function of $\log [\mathrm{HA}]-\log [\mathrm{H}+]$. The curves are valid for equal volumes of both phases. The maximum extraction is determined by $100 \lambda_{2}\left(1+\lambda_{2}\right)^{-1}$.

was confirmed experimentally by varying the amount of acetate buffer in the aqueous phase; no systematic deviations can be observed. As the acetate ion concentration must be kept below $0.005 \mathrm{M}$, the buffering capacity of the aqueous phase is not very large. We therefore believe that the scattering of the data in Fig. 1 is due in part to errors in the measurement of -log $\left[\mathrm{H}^{+}\right]$of the sampled aqueous layers. This error is of $c$ ourse not serious for the horizontal part of the curve.

The variation of $\log q$ with $\log [\mathrm{HA}]\left[\mathrm{H}^{+}\right]^{-1}$ plotted in Fig. 1 is ascribed wo reactions between $\mathrm{Cu}^{2+}$ and $\mathrm{HA}$ and we may compare the data with those in the study of the complex formation with nickel ${ }^{5}$ (cf. p. 57, Fig. 2 in that work; the signs of the two axes have there been reversed to simplify the comparison with solubility data). It may then be seen that the data can be fitted to the normalized curve ${ }^{5,11} Y=-\log \left(1+p v+v^{2}\right), X=-\log v$ with $p=0$ (full-drawn curve in Fig. 1), but not with $p=1$ (dotted). Thus no evidence is found of $\mathrm{CuA}^{+}$in appreciable amounts just as in the case with nickel ${ }^{5}$, and the same conclusion may be drawn about the parameter $p=\sqrt{K_{1} / K_{2}} \leq 0.25$. Using the value of the horizontal asymptote of the distribution curve, $\log \lambda_{2}=-0.93$, calculated from the data in Table 1 , we find from the position of the best fit with the other data for the reaction

the equilibrium constant|

$$
\mathrm{Cu}^{2+}+2 \mathrm{HA} \rightleftharpoons \mathrm{CuA}_{2}{ }^{\top}+2 \mathrm{H}^{+}
$$

$$
\log \beta_{2}+2 \log K_{\mathrm{a}}=-2(0.84 \pm 0.03)
$$

from the point of intersection between the asymptotes in Fig. 1. Using log $K_{\mathrm{a}}=-10.46$ calculated from solubility data ${ }^{5,12}$ we obtain $\log \beta_{2}=$ $19.24 \pm 0.06$.

We have thus determined the following set of equilibrium constants for the $\mathrm{CHCl}_{3}-0.1 \mathrm{M} \mathrm{NaClO}_{4}$ system at $25^{\circ} \mathrm{C}$ :

$$
\begin{aligned}
& \log \lambda_{2}:+2.51 \pm 0.10(\mathrm{Ni}) \text { and }-0.93 \pm 0.05(\mathrm{Cu}) \\
& \log \beta_{2}: \quad 17.24 \pm 0.07(\mathrm{Ni}) \text { and } 19.24 \pm 0.06(\mathrm{Cu})
\end{aligned}
$$

The distribution curves determined by these constants and $\log K_{\mathrm{a}}=-\mathbf{1 0 . 4 6}$ are shown as full-drawn curves in Fig. 1 . It may be seen that, at all values of 
$\log [\mathrm{HA}]\left[\mathrm{H}^{+}\right]^{-1}$, the extraction of $\mathrm{Ni}$ is much larger than the extraction of $\mathrm{Cu}$, the larger value of $\beta_{2}$ for $\mathrm{Cu}$ being unable to counterbalance the large difference in $\log \lambda_{2}$. Fig. 2 shows the percentage extraction for the two metals as a function of $\log [\mathrm{HA}]\left[\mathrm{H}^{+}\right]^{-1}$. The fact that nickel is readily extracted with dimethylglyoxime and chloroform while copper is not, is well-known to analytical chemists even if the explanations given hitherto have been based on insufficient experimental data.

The values of $\lambda_{2}$ and $\beta_{2}$ will be further discussed below.

\section{FORMATION OF MIXED COMPLEXES WITH QUINOLINE AND DODECYLAMINE}

The reason why $\lambda_{2}$ is so low for $\mathrm{Cu}_{2}$ in comparison with $\mathrm{NiA}_{2}$ is probably that $\mathrm{Cu}^{2+}$ in $\mathrm{CuA}_{2}$ has a tendency to coordinate with $\mathrm{H}_{2} \mathrm{O}$ and to be linked thereby with the water lattice. $\mathrm{NiA}_{2}$ on the other hand does not form any strong bonds with water, so it will have a fairly large value of $\lambda_{2}$. Dimethylglyoxime itself (HA) can form hydrogen bonds both as an acceptor and donor and consequently $K_{\mathrm{d}}$ is rather small.

If $\mathrm{Cu}^{2+}$ in $\mathrm{CuA}_{2}$ can be five-coordinated also in solution it should be possible to form a mixed complex (adduct) $\mathrm{CuA}_{2} \mathrm{~B}$ in the organic phase with a hydrophobic uncharged ligand $B$ (base) and thus increase the distribution ratio $q$ for copper:

$$
q=\frac{\left[\mathrm{CuA}_{2}\right]_{\mathrm{org}}+\left[\mathrm{CuA}_{2} \mathrm{~B}_{\mathrm{o1} 3}\right.}{\left[\mathrm{Cu}^{2}+\left[+\left[\mathrm{CuA}_{2}\right]\right.\right.}
$$

If we carry out the experiment in the range where ${ }_{-}^{*}\left[\mathrm{Cu}^{2+}\right]<<\left[\mathrm{CuA}_{2}\right]$ the expression for $q$ is simplified:

$$
q=\lambda_{2}+\lambda_{2} \varkappa_{\mathrm{B}}[\mathrm{B}]_{\mathrm{org}}
$$

Table 2. Distribution of $\mathrm{Cu}^{2}+$ between solutions of quinoline in chloroform and $0.1 \mathrm{M}$ perchlorate solutions buffered with acetate. The concentrations refer to the initial conc. in the aqueous (copper, dimethylglyoxime and acetate) or organic phase (quinoline).

\begin{tabular}{|c|c|c|c|c|c|}
\hline $\begin{array}{l}{[\mathrm{Cu}]_{\mathrm{tot}}} \\
10^{-4} \mathrm{M!}\end{array}$ & $\begin{array}{l}{[\mathrm{Ac}]_{\mathrm{tot}}{ }^{4}} \\
10^{-3} \mathrm{M}\end{array}$ & $\begin{array}{l}{[\mathrm{HA}]_{\text {tot }}} \\
10^{-3} \mathrm{M}\end{array}$ & $\begin{array}{c}{[\mathrm{B}]_{\text {tot }}} \\
10^{-3} \mathrm{M}\end{array}$ & $-\log [\mathrm{H}+]$ & $\log q$ \\
\hline 1.22 & 2.00 & 1.58 & 1.67 & 4.46 & -0.90 \\
\hline 0.988 & 3.33 & 1.58 & 3.33 & 4.30 & -0.83 \\
\hline 1.22 & 2.00 & 1.58 & 5.00 & 4.51 & -0.76 \\
\hline 0.395 & 3.33 & 1.57 & 6.66 & 4.43 & -0.74 \\
\hline 1.22 & 2.00 & 1.58 & 10.0 & 4.54 & -0.63 \\
\hline 0.395 & 3.33 & 1.57 & 16.7 & 4.47 & -0.50 \\
\hline 1.22 & 2.00 & 1.58 & 23.3 & 4.63 & -0.38 \\
\hline 1.15 & 1.67 & 2.09 & 33.3 & 4.20 & -0.33 \\
\hline 0.156 & 3.33 & 1.56 & 66.6 & 5.88 & -0.03 \\
\hline 0.156 & 3.33 & 1.56 & 133.5 & 6.03 & +0.28 \\
\hline 0.156 & 3.33 & 1.56 & 267 & 6.34 & +0.55 \\
\hline 1.15 & 1.67 & 2.09 & 534 & 4.86 & $\begin{array}{r}+0.79 \\
\end{array}$ \\
\hline 1.15 & 2.09 & 2.09 & 1000 & 5.37 & +1.02 \\
\hline
\end{tabular}

The data are plotted in Fig. 2 as $\log q$ against log [B] org.

Acta Chem. Scand. 15 (1961) No. 1 
Table 3. Distribution of $\mathrm{Cu}^{2}+$ between solutions of $n$-dodecylamine in chloroform and $0.1 \mathrm{M}$ perchlorate solutions buffered with $0.1 \mathrm{mmole}^{\mathrm{NH}} \mathrm{s}$ per $15 \mathrm{ml}$. The initial totel conc. of dimethylglyoxime in the aqueous phase was $1.66 \times 10^{-\mathrm{s}} \mathrm{M}$ and the value of $-\log \left[\mathrm{H}^{+}\right]$varies between 8.6-8.9.

$\begin{array}{llcc}{[\mathrm{Cu}]_{\text {tot }}} & \begin{array}{c}{[\mathrm{B}]_{\text {tot }}} \\ \mathrm{M}\end{array} & \log q & \log q-\log [\mathrm{B}]_{\text {org }} \\ \mathbf{1 0}-\mathrm{M} & 0.005 & 0.19 & \\ 0.479 & 0.0133 & 0.59 & 2.49 \\ 0.958 & 0.0133 & 0.56 & 2.47 \\ 0.0271 & 0.02 & 0.75 & 2.44 \\ 0.479 & 0.02 & 0.74 & 2.45 \\ 0.271 & 0.04 & 1.04 & 2.44 \\ 0.958 & 0.05 & 1.17 & 2.47 \\ 0.958 & 0.06 & 1.14 & 2.36 \\ 0.271 & 0.1 & 1.40 & 2.40 \\ 0.479 & 0.133 & 1.43 & 2.43 \\ 0.0271 & 0.22 & 1.55 & 2.43 \\ 0.0271 & 0.5 & 1.67 & 2.33 \\ 0.271 & 0.5 & 1.92 & 2.22 \\ 0.958 & 1 & 1.75 & 2.05 \\ 0.271 & 0.271 & 1.47 & 1.47\end{array}$

The mean value of $\log q[\mathrm{~B}]_{\text {org }}^{-1}$ for $[\mathrm{B}]_{\mathrm{tot}} \leq 0.22 \mathrm{M}$ is $2.43 \pm 0.05$, which is equal to $\log \lambda_{2} x_{B}$ (see text).

Quinoline and $n$-dodecylamine were chosen as B-ligands of different basicity. The hydrocar bon parts of these molecules are so large that the amount of $\mathrm{B}$ in the aqueous , hase is negligible *, and the formation of $\mathrm{CuA}_{2} \mathrm{~B}$ in the aqueous phase may therefore be neglected. The $\mathrm{pH}$ of the aqueous phase was so high that the amount of $\mathrm{BH}^{+}$could be neglected too.

The value of $\lambda_{2}$ for $\mathrm{Ni}$ is so large $\left(\log \lambda_{2}=2.51\right)$ that the distribution method is not very suitable for a study of a complex formation between $\mathrm{NiA}_{2}$ and quinoline and dodecylamine. We therefore chose to study the solubility of $\mathrm{NiA}_{2}$ in chloroform solutions of quinoline and dodecylamine. The same method was also used to study reactions between $\mathrm{HA}$ and $\mathrm{B}$ (see below the results with $\mathrm{CuA}_{2}$ and $\mathrm{NiA}_{2}$ ).

Results. The data are given in Tables 2 ( $\mathrm{CuA}_{2}$-quinoline), 3 (CuA $\mathrm{Cu}_{2}$-dodecylamine), 4 (HA-quinoline), and 5 (HA-dodecylamine). The copper data are plotted in Fig. 3 and the HA-data in Fig. 5 as $\log q$ and $\log S$ against $\log [\mathrm{B}]_{\text {org. }}$.

The data with quinoline in Fig. 3 can be fitted with the normalized 11 curve $Y=\log (1+v) ; X=\log v$, which indicates that in addition to $\mathrm{CuA}_{2}\left(\mathrm{H}_{2} \mathrm{O}\right)_{x}$ ( $\mathrm{x}$ is not determined in these experiments where the activity of $\mathrm{H}_{2} \mathrm{O}$ is constant) a $1: 1$ complex is formed with quinoline and that $\mathrm{Cu}^{2+}$ can attain a coordination number of at least five in $\mathrm{CuA}_{2}$. No experiments with dodecylamine were made with $[\mathrm{B}]_{\text {org }}$ between 0 and $0.005 \mathrm{M}$ since it was feared that the correction for the amount of dodecylamine bound to HA would be too large (see below). For this reason we did not obtain the part of

* The distribution constant of quinoline between chloroform and $0.1 \mathrm{M} \mathrm{NaClO}$, was deter. mined as $471 \pm 3$ by S. Ekberg. 


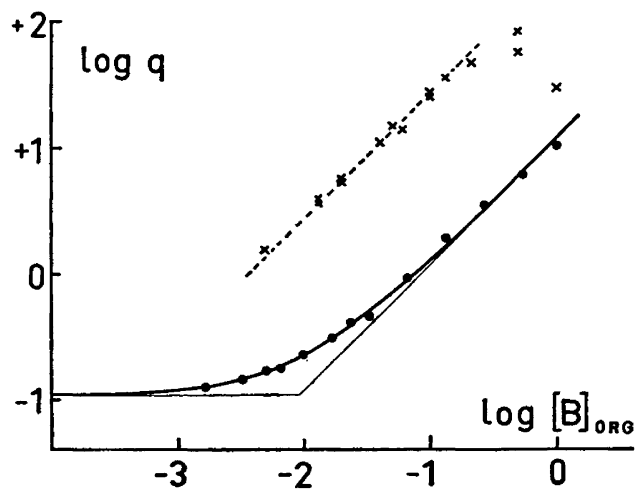

Fig. 3. Distribution of copper between chloroform and $0.1 \mathrm{M} \mathrm{NaClO}$ as a function of the quinoline (full-drawn curve) or dodecylamine (dashed line with slope 1) concentration in the chloroform nhese. The normalised curve $Y=\log (1+v), X=\log v$ is fitted to the data.

the curve, where appreciable amounts of both $\mathrm{CuA}_{2}$ and $\mathrm{CuA}_{2} \mathrm{~B}$ are present in the organic phase. Deviations at $[\mathrm{B}]_{\text {org }}>0.22 \mathrm{M}$ are probably due to the self-association of dodecylamine in chloroform (cf. Fig. 5).

The equilibrium constant $x_{\mathrm{B}}$ of the reaction $\mathrm{CuA}_{2}$ (in $\mathrm{CHCl}_{3}$ ) $+\mathrm{B}$ (in $\mathrm{CHCl}_{3}$ ) $\rightleftharpoons \mathrm{CuA}_{2} \mathrm{~B}$ (in $\mathrm{CHCl}_{3}$ ) is obtained from the intercept of the two asymptotes, $\log q=\log \lambda_{2}(Y=0)$ and $\log q=\log \lambda_{2} x_{\mathrm{B}}[\mathrm{B}]_{\mathrm{org}}(Y=X)$, to the curve (Fig. 3):

$$
\begin{aligned}
& \log \varkappa_{\mathrm{B}}=2.04(\mathrm{~B}=\text { quinoline }) \\
& \log \varkappa_{\mathrm{B}}=3.36(\mathrm{~B}=\text { dodecylamine })
\end{aligned}
$$

Fig. 4 shows that the solubility of $\mathrm{NiA}_{2}$ is very little increased by the addition of quinoline or dodecylamine to the chloroform phase; the decrease at high $[\mathrm{B}]_{\text {org }}$ is probably due to self-association of $\mathrm{B}$. From the experiments we conclude that $\mathrm{Ni}^{2+}$ is four-coordinated in $\mathrm{NiA}_{2}$. The value of the solubility of $\mathrm{NiA}_{2}$ in chloroform, saturated with water, obtained by us is $4.75 \times 10^{-4} \mathrm{M}$, which agrees very well with the value of $4.8 \times 10^{-4} \mathrm{M}$ determined by Christopherson and Sandell ${ }^{12}$, who saturated their solutions by shaking for 6 hours.

Fig. 4. Solubility of $\mathrm{NiA}_{2}$ in solutions of quinoline $(0)$ or dodecylamine $(x)$ in

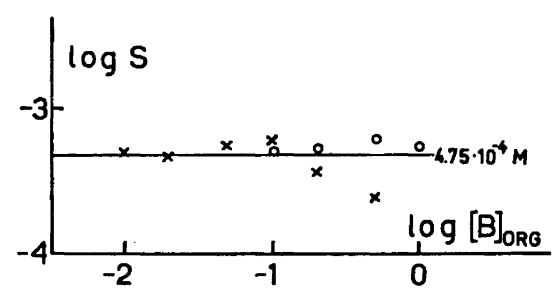

Acta Chem. Scand. 15 (1961) No. 1 


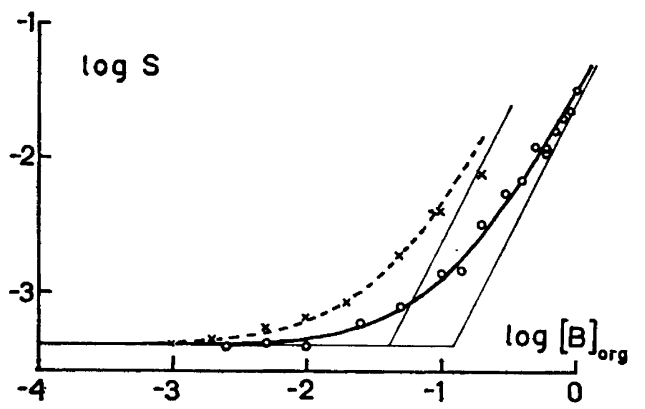

Fig. 5. The solubility of dimethylglyoxime in chloroform as a function of the conc. of quinoline (full-drawn curve) or dodecylamine (dashed curve). The normalised curve $\underline{Y}=\log \left(1+p v+v^{2}\right), X=\log v$ is fitted to the data. The best fit was obtained with $p=2$.

Table 4. Solubility of dimethylglyoxime in wet chloroform solutions of quinoline at $25^{\circ} \mathrm{C}$. Values of $S$ in mmoles per liter and molar conc. of quinoline: $0.392(0), 0.391(0.0025)$, 0.405 (0.005), $0.389(0.01), 0.583(0.025), 0.769(0.05), 1.383(0.1), 1.430(0.14), 3.20(0.2)$, $5.36(0.3), 6.79(0.4), 11.98(0.5), 11.47(0.6), 10.64(0.6), 15.53(0.7), 19.58(0.8), 22.4$ $(0.9), 32.0$ (1).

Table 5. Solubility of dimethylglyoxime in wet chloroform solutions of dodecylamine at $25^{\circ} \mathrm{C}$. Values of $S$ in mmoles per liter and molar conc. of dodecylamine: $0.403(0.00098)$, $0.439(0.00196), 0.534(0.0049), 0.638(0.0098), 0.823(0.0196), 1.86(0.049), 3.97(0.098)$, $7.42(0.196)$.

Table 6. Distribution of $\mathrm{Cu}^{2}+$ between chloroform and aqueous solutions containing dimethylglyoxime and $\mathrm{NH}_{2}$. Values of $\log q$ and molar conc. of $\mathrm{NH}_{3}$ in the aqueous phase: $-0.91(0.0067),-0.81(0.0333),-0.91(0.167),-1.31(0.6)$.

That also $B$ can react with dimethylglyoxime itself is obvious from Tables 4 and 5 and Fig. 5, which shows the increase of the solubility of HA with [B] $]_{\text {org. The data seem }}$ to approach a line with slope 2, which corresponds to the formation of $\mathrm{HAB}_{2}$; each hydrogen in the oxime groups seems to form a hydrogen bond with the acceptor molecule B. Using the technique of curve-fitting ${ }^{11,13}$ it was found that a curve $Y=\log$ $\left(1+2 v+v^{2}\right), X=\log v$ fitted the data reasonably well except for dodecylamine concentrations above $0.1 \mathrm{M}$ where probably self-association occurs (cf. Fig. 3). The equation of the curves can be derived as follows.

$$
S=[\mathrm{HA}]+[\mathrm{HAB}]+\left[\mathrm{HAB}_{2}\right]=[\mathrm{HA}]\left(1+K_{\mathrm{B}}[\mathrm{B}]_{\mathrm{org}_{\mathrm{rg}}}+K_{\mathrm{B} 2}[\mathrm{~B}]^{2} \mathrm{org}\right)
$$

The equations of the two asymptotes to the curve $\log S\left(\log [\mathrm{B}]_{\mathrm{org}}\right)$ are

$$
\begin{aligned}
& \log S=\log [\mathrm{HA}]=\log S_{0} \\
& \log S=\log S_{0} K_{\mathrm{B} 2}[\mathrm{~B}]_{\text {org }}^{2}
\end{aligned}
$$

The parameters $S_{0}$ and $K_{\mathrm{B} 2}$ are obtained from the point of intercept of the asymptotes: $S_{0}=3.94 \times 10^{-4} \mathrm{M}$ and $\log K_{\mathrm{B} 2}=1.80$ (quinoline) and 2.74 (dodecylamine). From the difference between $S$ and $S_{0}$ at this point we obtain $K_{\mathrm{B}}: \log K_{\mathrm{B}}=1.20$ (quinoline) and 1.67 (dodecylamine) (cf. Ref. ${ }^{13}$ ). The value of $S_{0}$ agrees fairly well with Christopherson and Sandell's value ${ }^{12} 4.5 \times 10^{-4} \mathrm{M}$ and very well with the value of Babko and Mikkel'son $^{14} 3.96 \times 10^{-4} \mathrm{M}$. 
The reactions between HA and B lower the value of [HA] in the aqueous phase, and will disturb an investigation of the complex formation of $\mathrm{MA}_{2}$ and $\mathrm{B}$ if the value of $\log$ $[\mathrm{HA}][\mathrm{H}+]^{-1}$ is not sufficiently high. With quinoline the correction in the calculation of the conc. of free $\mathrm{B},[\mathrm{B}]_{\mathrm{org}}$, is small as the total conc. of $\mathrm{HA}$ is always below $0.0021 \mathrm{M}$. This is not quite true with dodecylamine, which reacts more readily with HA.

\section{REACTIONS BETWEEN CuA $\mathrm{A}_{2}$ AND $\mathrm{NH}_{3}$}

The investigations with quinoline and dodecylamine showed clearly that $\mathrm{CuA}_{2}$ could react with a base in chloroform and it was therefore thought worthwhile to see if the distribution ratio of copper could be lowered by the addition of $\mathrm{NH}_{3}$ to the aqueous phase. Such an experiment might indicate the existence of a five-coordinated copper complex, $\mathrm{CuA}_{2} \mathrm{NH}_{3}$. The data in Table 6 show, however, that $q$ is very little affected by the addition of $\mathrm{NH}_{3}$ at $\mathrm{pH}$ where the hydrolysis of $\mathrm{CuA}_{2}$ may be neglected (see below). We therefore conclude that for $\mathrm{NH}_{3}$-concentrations less than $0.2 \mathrm{M}, \mathrm{CuA}_{2}\left(\mathrm{H}_{2} \mathrm{O}\right)$ is the dominating complex in the aqueous phase. This is in agreement with the fact that the equilibrium constant for the reaction $\mathrm{Cu}\left(\mathrm{NH}_{3}\right)_{4}^{2+}+\mathrm{NH}_{3} \rightleftharpoons \mathrm{Cu}\left(\mathrm{NH}_{3}\right)_{5}^{2+}$ is small ${ }^{15}$. It can then be concluded that the method ${ }^{16}$ of removing $\mathrm{CuA}_{2}$ from the chloroform layer by shaking the chloroform with dilute ammonia, is an effect due to a low value of $\lambda_{2}$, and not due to the formation of a $\mathrm{CuA}_{2} \mathrm{NH}_{3}$ complex. In this procedure the nickel content in the organic phase is not appreciably lowered ${ }^{16}$ if the $\mathrm{pH}$ is sufficiently high.

\section{THE SOLUBILITIES OF $\mathrm{NiA}_{2}$ AND $\mathrm{CuA}_{2}$}

It is a well-known fact that the $\mathrm{Ni}^{2+}$ but not $\mathrm{Cu}^{2+}$ may be precipitated from aqueous solutions with dimethylglyoxime. Following Godycki and Rundle ${ }^{2}$, Sharpe and Wakefield ${ }^{17}$ suggested that the forces in the solid state and especially the $\mathrm{Ni}-\mathrm{Ni}$ bond offered an explanation of the great difference in solubility between the copper and nickel complex. The new X-ray data ${ }^{1}$ on $\mathrm{CuA}_{2}$ and the fact that $\mathrm{CuA}_{2}$ is known to be less extractable ${ }^{18}$ than $\mathrm{NiA}_{2}$ in spite of the fact that $\mathrm{Cu}^{2+}$ forms stronger complexes ${ }^{19}$, suggested, however, that solvation effects should be much more important.

If this was true the solubility of the two salts in an organic non-solvating solvent should not be very different. We obtained the following results for chloroform, which presumably does not coordinate with the central atom:

For $\mathrm{NiA}_{2}: 4.75 \times 10^{-4} \mathrm{M}$ (wet)

For $\mathrm{CuA}_{2}: 10.5_{3} \times 10^{-4} \mathrm{M}$ (wet) and $10.2_{3} \times 10^{-4} \mathrm{M}$ (dry)

The values of the solubilities of the salts in $0.1 \mathrm{M} \mathrm{NaClO}_{4}$ saturated with chloroform can be estimated by dividing the solubilities in chloroform with $\lambda_{2}$ :

For $\mathrm{NiA}_{2}: \lambda_{2}^{-1} \times 4.75 \times 10^{-4}=(1.5 \pm 0.3) 10^{-6} \mathrm{M}$

For $\mathrm{CuA}_{2}: \lambda_{2}^{-1} \times 10.5_{3} \times 10^{-4}=(9 \pm 1) 10^{-3} \mathrm{M}$

The estimated value for $\mathrm{NiA}_{2}$ agrees fairly well with a value given by Christopherson and Sandell ${ }^{12}$ for $0.05 \mathrm{M} \mathrm{NaCl}$ saturated with $\mathrm{CHCl}_{3}: 1.23 \times 10^{-6} \mathrm{M}$ and for $\mathrm{CuA}_{2}$ in $0.1 \mathrm{M} \mathrm{NaClO}_{4}$ the value measured by us is $7.9_{1} \times 10^{-3} \mathrm{M}$, which also agrees reasonably well with the estimated value. 


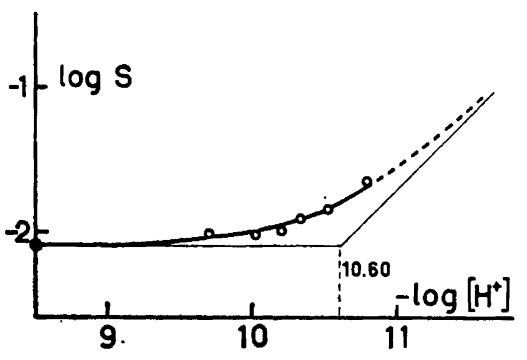

Fig. 6. The solubility of $\mathrm{CuA}_{2}$ in $0.1 \mathrm{M}$ $\mathrm{Na}\left(\mathrm{OH}, \mathrm{ClO}_{4}\right)$ as a function of $-\log \left[\mathrm{H}^{+}\right]$. The normalised curve $Y=\log (1+v)$; $X=\log v$ is fitted to the data utilizing the solubility in $0.1 \mathrm{M} \mathrm{NaClO}_{\&}, 7.91 \times 10^{-3}$ M, $\log S=-2.10$, as the value of the horizontal asymptote (thin line).

From these experiments we conclude that lattice the energies of the two salts are about the same, and that the large difference in water-solubility must be due to solvation of $\mathrm{CuA}_{2}$, which thereby is linked to the water lattice. Furthermore, we conclude from the solubilities of $\mathrm{CuA}_{2}$ in dry and wet chloroform, that the complex may be unhydrated in wet chloroform. This conclusion could not be drawn from the distribution experiments.

The crystal structure of $\mathrm{CuA}_{2}$ and experiments reported above suggest that copper may be five-coordinated in $\mathrm{CuA}_{2}$ and form a monohydrate, $\mathrm{CuA}_{2}\left(\mathrm{H}_{2} \mathrm{O}\right)$, in water. The low solubility of $\mathrm{NiA}_{2}$ in water is then partly due to the forces in the solid state and partly to the fact that it contains hydrophobic groups and no tendency to be five- or six-coordinated (and solvated). The importance of the forces in the solid state (but not necessarily the $\mathrm{Ni}-\mathrm{Ni}$ bond) is shown by the fact that the ethylmethylglyoxime nickel salt is more soluble in water ${ }^{20}$ despite the increased size of the hydrophobic groups. How much the long $\mathrm{Ni}-\mathrm{Ni}$ bond contributes to the lattice energy is still open to speculation.

\section{THE HYDROLYSIS OF $\mathrm{CuA}_{2} \mathrm{H}_{2} \mathrm{O}$}

If it is correct that $\mathrm{CuA}_{2}$ can coordinate with a water molecule it should be possible to find a complex $\mathrm{CuA}_{2} \mathrm{OH}^{-}$in alkaline solutions provided the hydrolysis of $\mathrm{CuA}_{2} \mathrm{H}_{2} \mathrm{O}$ is not too weak.

As chloroform reacts with alkali we preferred to study the hydrolysis of $\mathrm{Cu}_{2} \mathrm{H}_{2} \mathrm{O}$ by measuring the solubility of $\mathrm{CuA}_{2}$ in $0.1 \mathrm{M} \mathrm{Na}\left(\mathrm{OH}, \mathrm{ClO}_{4}\right)$ as a function of $-\log \left[\mathrm{H}^{+}\right]$. As seen from Fig. 6 the solubility increases with $\mathrm{pH}$ $\left(-\log \left[\mathrm{H}^{+}\right]\right)$and the data could be fitted to the normalized curve $Y=\log$ $(1+v), X=\log v$. In addition to $\mathrm{CuA}_{2}$ there must then be a complex with one proton less than in $\mathrm{CuA}_{2}$. Our guess is $\mathrm{CuA}_{2} \mathrm{OH}^{-}$, but the proton can equally well come from one of the hydrogen bridges in $\mathrm{CuA}_{2}$. To explain the experimental curve we shall write the solubility of $\mathrm{CuA}_{2}$ as

$$
S=\left[\mathrm{CuA}_{2} \mathrm{H}_{2} \mathrm{O}\right]+\left[\mathrm{CuA}_{2} \mathrm{OH}^{-}\right]=\left[\mathrm{CuA}_{2} \mathrm{H}_{2} \mathrm{O}\right]\left(1+x_{\mathrm{H}}\left[\mathrm{H}^{+}\right]^{-1}\right)
$$

In the neutral range $\left(0.1 \mathrm{M} \mathrm{NaClO}_{4}\right)$

$$
S=\left[\mathrm{CuA}_{2} \mathrm{H}_{2} \mathrm{O}\right]=7.9 \mathrm{I} \times 10^{-3} \mathrm{M}
$$

We then obtain

$$
\log S=-2.10+\log \left(1+\varkappa_{\mathrm{H}}\left[\mathrm{H}^{+}\right]^{-1}\right)
$$

Acta Chem. Scand. 15 (1961) No. 1 
The constant $\varkappa_{\mathrm{H}}$ may be found from the position of the asymptotes to the curve at the best fit: $\log x_{\mathrm{H}}=-10.60$.

This value may be compared ${ }^{15}$ with $\log * K_{1} \sim-7$ for the hydrolysis of $\mathrm{Cu}\left(\mathrm{H}_{2} \mathrm{O}\right)_{n}^{2+}$. Obviously, the hydrolysis of $\mathrm{CuA}_{2} \mathrm{H}_{2} \mathrm{O}$ is much weaker than the hydrolysis of the charged aqueous complex. Alternatively it can be said that the complex formation with the strong base $\mathrm{OH}^{-}$is much weaker. Using $\log \left[\mathrm{H}^{+}\right]\left[\mathrm{OH}^{-}\right]=-13.81$ in $0.1 \mathrm{M} \mathrm{NaClO}$ we may calculate $\log K_{1}$ as 3.21 for $\mathrm{CuA}_{2}+\mathrm{OH}^{-} \rightleftharpoons \mathrm{CuA}_{2} \mathrm{OH}^{-}$.

\section{CONCLUSIONS}

From distribution experiments no evidence is found of the presence of significant amounts of $\mathrm{CuA}^{+}$, and it is concluded that $\log K_{1} \leq \log K_{2}-1.2$ as in the case of nickel ${ }^{5}$. As this is not true for either ethylenediamine ${ }^{15}$, acetylacetone ${ }^{15}$, or $\beta$-isopropyltropolone ${ }^{21,22}$ we conclude that the formation of the second complex is favored by the formation of two hydrogen bonds.

The distribution of copper can be increased by the addition of a base (quinoline or dodecylamine) to the chloroform phase. The reaction, which is an example of the so-called "synergic" effect ${ }^{24}$, can be written as follows:

$$
\mathrm{CuA}_{2} \text { (org) }+\mathrm{B} \text { (org) } \rightleftharpoons \mathrm{CuA}_{2} \mathrm{~B} \text { (org) (eq. const. } \varkappa_{\mathrm{B}} \text { ) }
$$

Dodecylamine is a stronger base than quinoline and consequently gives a higher value of $\varkappa_{B}$. The solubility of $\mathrm{NiA}_{2}$ in chloroform is very little affected by the addition of quinoline or dodecylamine. From these experiments it is concluded that $\mathrm{Cu}^{2+}$ has a tendency to be five-coordinated in $\mathrm{CuA}_{2}$ while $\mathrm{Ni}^{2+}$ in $\mathrm{NiA}_{2}$ has not.

From the values of the distribution constants of $\mathrm{NiA}_{2}$ and $\mathrm{CuA}_{2}$ it is concluded that the large difference can only be explained by the fact that the $\mathrm{CuA}_{2}$ complex is solvated in the aqueous phase. $\mathrm{As} \mathrm{CuA}_{2}$ is five-coordinated in the crystal state as well as in chloroform solutions of quinoline or dodecylamine it seems probable that the primary complex in the aqueous phase is $\mathrm{CuA}_{2} \mathrm{H}_{2} \mathrm{O}$. This complex is then linked with the water lattice. - For $\beta$-isopropyltropolone ${ }^{22}$ we obtained $\lambda_{2}(\mathrm{Cu})>10000>\lambda_{2}(\mathrm{Ni})>100$, and the copper salt of tropolone is planar (four-coordination) in the crystal state ${ }^{23}$. The difference between dimethylglyoxime and $\beta$-isopropyltropolone as chelate-forming ligands may be explained by the smaller tendency of the two dimethylglyoximate ions to fill the electron gaps in the $\mathrm{Cu}^{2+}$ ion. In the $\mathrm{Cu}$ (II) diisopropyltropolonate complex the gaps are probably more effectively filled and no coordination power is left.

The solubilities of $\mathrm{NiA}_{2}$ and $\mathrm{CuA}_{2}$ have been determined in wet chloroform, and were found to be not very different. From these experiments it is concluded that the lattice energy is about the same for both complexes and that the long $\mathrm{Ni}-\mathrm{Ni}$ bonds in $\mathrm{NiA}_{2}$ are weak. The large difference in water solubility can be explained by the solvation of $\mathrm{CuA}_{2}$ and is a consequence of the tendency of $\mathrm{Cu}^{2+}$ to be five-coordinated in $\mathrm{CuA}_{2}$. The low solubility of $\mathrm{NiA}_{2}$ in water is an effect of the weak tendency of $\mathrm{NiA}_{2}$ to co-ordinate water molecules. 
As $\mathrm{pH}$ increases, the solubility of $\mathrm{CuA}_{2}$ in $0.1 \mathrm{M} \mathrm{Na}\left(\mathrm{OH}, \mathrm{ClO}_{4}\right)$ will increase The data show that one proton comes off, and our guess is that this is not a proton from one of the two strong hydrogen bridges but one from the associated water molecule in $\mathrm{CuA}_{2} \mathrm{H}_{2} \mathrm{O}$.

Note. When our work was completed we obtained a microfilm of a thesis by $D$. Fleischer ${ }^{25}$ with the title "A thermodynamic study of some factors affecting the stability and solubility of metal chelates". This work contains a determination of the solubilities of the nickel and copper salts of dimethylglyoxime in water, chloroform, benzene and $n$-heptane at various temperatures. The following values were obtained at $25^{\circ} \mathrm{C}(\mathrm{Ni}$, $\mathrm{Cu}): 1.05 \times 10^{-6}, 5.68 \times 10^{-3} \mathrm{M}\left(\mathrm{H}_{2} \mathrm{O}\right) ; 4.62 \times 10^{-4} ; 1.24 \times 10^{-3} \mathrm{M}\left(\mathrm{CHCl}_{3}\right) ; 7.53 \times 10^{-5}$, $4.5 \times 10^{-5} \mathrm{M}\left(\mathrm{C}_{6} \mathrm{H}_{6}\right) ; 2.5 \times 10^{-7}, 1.84 \times 10^{-7} \mathrm{M}\left(\mathrm{C}_{7} \mathrm{H}_{16}\right)$. The values for water and chloroform are not very different from our values. The heats of solution $\left(\triangle H^{\circ}\right)$ in water were $9.0 \mathrm{kcal}(\mathrm{Ni})$ and $0.0 \mathrm{kcal}(\mathrm{Cu})$. According to Fleischer ${ }^{25}$ this difference must be due to larger solvation energy of $\mathrm{CuA}_{2}$ in water and to the fact that copper can exhibit a coordination number higher than four. Fleischer ${ }^{25}$ also states that the addition of $n$ butylamine permitted quantitive extraction of $\mathrm{CuA}_{2}$ into chloroform. From the solubilities in benzene and heptane Fleischer ${ }^{25}$ concludes that the crystalline $\mathrm{CuA}_{2}$ is more stable than $\mathrm{NiA}_{2}$ by about two or three kilocalories. On the whole Fleischer's data and conclusions agree with our results, and as the two investigations have been carried out independently still more reliance can be placed on the present explanation of the chemical differences between $\mathrm{NiA}_{2}$ and $\mathrm{CuA}_{2}$.

Note added in proof. The spectra of $5 \times 10^{-4} \mathrm{M} \mathrm{CuA}_{2}$ in $0.1 \mathrm{M} \mathrm{NaClO}_{4}$ with $1.503 \times$ $10^{-3} \mathrm{M}$ HA has recently been studied in our laboratory as a function of $-\log \left[\mathrm{H}^{+}\right]$by Mrs. Solveig Ekberg and Mr. Sven Hansson. The light absorption between 350 and 450 $\mathrm{m} \mu$ increases from 10 to $90 \%$ between $-\log [\mathrm{H}+]=3$ and 4 , but the shape of the curve remains unchanged. As neither $\mathrm{Cu}^{2}+$ nor $\mathrm{HA}$ absorbs light in this region, the experiments indicate that below $\mathrm{pH}=7 \mathrm{CuA}_{2}$ is the only complex formed: $\mathrm{Cu}^{2}++2 \mathrm{HA} \rightleftharpoons \mathrm{CuA}_{2}$ $+2 \mathrm{H}+$. From the data the equilibrium constant of this reaction could be calculated as $\log \beta_{2} \dot{K}_{\mathrm{a}}^{2}=-2(0.85 \pm 0.04)$. This value is in complete agreement with the result from the extraction work reported above.

Acknowledgements. The present invastigation has been supported by the Swedish Council for Atomic Research (AFR) and Swedish Natural Science Research Council (NFR). Valuable criticism on the manuscript has been made by the head of the department, professor Lars Gunnar Sillén. The English has been revised by Dr. Valentine Tyrrell.

\section{REFERENCES}

1. Frasson, E., Bardi, R. and Bezzi, S. Acta Cryst. 12 (1959) 201.

2. Godycki, L. E. and Rundle, R. E. Acta Cryst. 6 (1953) 487.

3. Pearson, W. B. Lattice Spacings and Structures of Metals and Alloys, Pergamon Press, London 1957.

4. Haendler, H. M., Patterson, W. L., Jr. and Bernard, W. J. J. Am. Chem. Soc. 74 (1952) 3167.

5. Dyrssen, D., Krašovec, F. and Sillén, L. G. Acta Chem. Scand. 13 (1959) 50.

6. "Some laboratory methods ..., , Department of Inorganic Chemistry, Royal Institute of Technology, Stockholm", manuscript, 1959.

7. Tschugaeff, L. Z. anorg. Chem. 46 (1905) 144.

8. Higgins, C. E. and Baldwin, W. H. Anal. Chem. 32 (1960) 236.

9. Pedersen, K. J. Kgl. Danske Vidensk. Selskab. Math.-fys. Medd. 22 (1945) No. 12.

10. Kielland, J. J. Am. Chem. Soc. 59 (1937) 1675.

11. Sillén, L. G. Acta Chem. Scand. 10 (1956) 186.

12. Christopherson, H. and Sandell, E. B. Anal. Chem. Acta 10 (1954) 1.

13. Dyrssen, D. and Sillón, L. G. Acta Chem. Scand. 7 (1953) 663.

14. Babko, A. K. and Mikkel'son, P. B. Ukrain. Khim. Zhur. 21 (1955) 388. 
15. Bjerrum, J., Schwarzenbach, G. and Sillén, L. G. Stability Constants I and II, The Chemical Society, Spec. Publ. No. 6 and 7, London 1958.

16. Alexander, O. R., Godar, E. M. and Linde, N. J. Ind. Eng. Chem., Anal. Ed. 18 (1946) 206.

17. Sharpe, A. G. and Wakefield, D. B. J. Chem. Soc. 1957281.

18. Sandell, E. B. Colorimetric Determinations of Traces of Metals, Interscience Publishers, New York 1950.

19. Charles, R. G. and Freiser, H. Anal. Chim. Acta 11 (1954) 101.

20. Cox, E. G., Sharratt, E., Wardlaw, W. and Webster, K. C. J. Chem. Soc. 1936129.

21. Dyrssen, D. Intern. Conf. on Coordination Chemistry, London 1959.

22. Dyrssen, D. To be published.

23. Robertson, J. M. J. Chem. Soc. 19511222.

24. Irving, H. and Edgington, D. N. Proc. Chem. Soc. 1959360.

25. Fleischer, D. Thesis, Univ. Pittsburgh 1959, Univ. Microfilms 59-2396, Ann Arbor, Michigan.

Received August 31, 1960. 